\title{
O Messias e a prostituta
}

\author{
Henrique Marques-Samyn*
}

\section{Introdução}

Até os dias de hoje permanecia inédita a singular obra de Mordecai Maggid, autor do conto que a seguir apresentamos e sobre o qual esboçaremos alguns comentários; contudo, em primeiro lugar, cabe apresentar os parcos dados biográficos de que dispomos acerca deste original escritor.

Mordecai Maggid faleceu em 1998 ou 1999, deixando várias pastas com manuscritos inéditos contendo obras literárias - poemas, contos e um romance inacabado -, além de alguns ensaios e aforismos; após uma vida tão curta quanto tormentosa, morreu na miséria. Segundo o que sabemos - e que nos foi contado por seu único amigo íntimo, cujo nome mantemos em segredo por solicitação do próprio -, Mordecai levou uma vida normal até os 15 anos, época em que se descobriu descendente de uma "polaca", ou seja, uma prostituta judia da Europa Central. A revelação causou-lhe um profundo impacto: até aquele momento, o jovem aparentemente não tinha qualquer consciência de sua ascendência judaica; após a descoberta, assumiu o pseudônimo através do qual o conhecemos e tornou-se um religioso devotado - para não dizer obsessivo.

De acordo com nossa fonte, Mordecai Maggid era filho de uma judia não-praticante e de um ateu, o que causou profundas tensões domésticas devido ao radicalismo com que o jovem abraçou sua fé. Mordecai cumpria todos os 613 preceitos da lei mosaica, vestia-se como um chassid e dedicou-se ao estudo da língua hebraica (que chegou a conhecer com espantosa profundidade para um autodidata) e às práticas cabalísticas. Apenas um ano após a revelação, foi expulso de casa pelos pais na época de Pessach, quando sua estrita observância levou-o a revirar toda a casa e a queimar todos os alimentos fermentados ali presentes.

Com o dinheiro que the fora cedido por seu pai, alugou um casebre no bairro de Olaria, no Rio de Janeiro; ali passou a viver, dedicando-se aos seus escritos e às suas práticas místicas. Incapaz de prover seu próprio sustento, Mordecai Maggid vivia como um mendigo; embora recebesse ajuda da comunidade judaica local, sua saúde piorou progressivamente, sobretudo devido aos hábitos ascéticos que passou a cultivar a fim de, como afirmava, purificar sua alma dos pecados de seus antepassados. Aos 19 anos, Mordecai faleceu e como seu desejo de ser enterrado em um cemitério israelita foi negado pelas autoridades judaicas, seu cadáver foi destinado à cremação por ordem de seus pais.

O conto que a seguir apresentamos aparece entre os manuscritos sem título. Desse modo, o título que aqui recebe foi por nós atribuído. Seu tema é bastante comum nas obras de Mordecai Maggid, que tinha um interesse especial por personalidades marginais e controversas dentro do judaísmo. Encontramos em seu espólio, também, textos sobre outras figuras messiânicas, como Asher Kay e Jacob Frank. Em todos esses relatos, observa-se uma mescla de referências históricas com criações ficcionais. O conto sobre Sabatai Zvi é, dentre todos, o que podemos considerar o mais fiel à História, embora, evidentemente, boa parte dele seja produto da imaginação de seu autor.

O conto é dividido em três partes numeradas, cada uma das quais se encontra introduzida por um termo hebraico (nesta publicação, por motivos editoriais, os vocábulos foram transliterados); esses termos encontram-se riscados no manuscrito, o que possivelmente indica uma intenção do autor de excluí-los da versão final. Curiosamente, são essas as únicas palavras 
do conto escritas em alfabeto hebraico: todos os outros vocábulos hebraicos que nele encontramos encontram-se transliterados. Há provavelmente um sentido simbólico no emprego desses termos, uma vez que correspondem a conceitos relacionados à alma humana; de forma necessariamente reducionista, poderíamos afirmar que Nefesh corresponde ao nível vegetativo; Ruach ao espiritual e emocional e Neshamah ao divino e intelectual. Não nos arriscaremos aqui a oferecer interpretações para o sentido desses vocábulos no âmbito ficcional, deixando-as a cargo do leitor.

Rio de Janeiro, dezembro de 2008.

Helena Molko-Sheria

\section{O Messias e a prostituta: um conto de Mordecai Maggid}

\section{$1 /$ Nefesh}

É capaz de descer das alturas aos abismos de uma hora para a outra. Tem sido assim desde a sua juventude; neste momento, atravessa um de seus momentos sombrios e, por isso, seu semblante expressa uma densa e profunda angústia. Está aflito - não pode ocultá-lo: tem trêmulas as mãos, os olhos frementes, a voz hesitante. Percebem aqueles que o acompanham, mas têm suas explicações: é o momento da queda, dizem, a queda que se segue inevitavelmente à iluminação - porque assim é seu conturbado espírito: de um momento para o outro, pode descer dos mais altos degraus para os mais profundos precipícios, lá onde se vê cercado por todos os demônios.

Tem sido assim desde a sua juventude - e desde a sua juventude ele procurou uma forma de se livrar desse peso. Devia se disciplinar, domar a alma tortuosa: se ofereceu ao látego, emulando Luria, e se lançou ferozmente à luta pelo tikun. Vislumbrou em cada um de seus atos - em cada pequeno, em cada mínimo gesto - o processo de restauração divina pelo qual também ele era responsável. Era preciso fazê-lo: dominar a carne, fustigar cada parte do corpo com o flagelo da vontade, e assim arduamente escavar a estrada que o levaria à sua própria salvação; uma solitária luta. Quantos não tentaram desviá-lo do reto caminho? Inclusive elas, as mulheres que o tentaram levar à perdição - antes que houvesse Sara. Era ainda muito jovem quando o obrigaram a se casar com a primeira delas. Ele, no entanto, teve a força necessária para rechaçar cada um dos demônios - não tocou, não tocaria o seu corpo: não se deitaria no leito, não conheceria aquela carne. E assim fez, e assim lutou até que ela, enfastiada, o deixou. Quando lhe arranjaram uma segunda esposa, lutou com a mesma tenacidade. No belo corpo, via as ásperas pedras que ansiavam por ferir seu espírito. Ele a rechaçou, e ele outra vez foi rechaçado. Já se abriam - ele as entrevia - as portas da esperada redenção. Já podia sentir a paz roçando a sua ferida pele - sobretudo quando, durante o inverno, se atirava ao mar. O maldito corpo, já esmorecido pelo longo jejum, era dilapidado pelas águas geladas, alçando sua alma ao êxtase, trazendo a almejada trégua aos embates de seu espírito.

As épocas de tranqüilidade, contudo, eram breves e raras e, mesmo que se dedicasse ainda com mais afinco à mortificação do corpo, as trevas subitamente retornavam e, de um golpe, o arrastavam outra vez para as profundezas, quando já não mais tinha o controle de seus próprios gestos. E foi num desses momentos que lhe veio a revelação, quando de repente a certeza lhe brotou no espírito e as palavras jorraram de entre os flébeis dentes; os olhos dos que o rodeavam se arregalaram quando o ouviram dizer, com as pálpebras semicerradas e uma voz grave e gutural, as mãos tremendo em leve espasmo, o nome de Deus, o sagrado nome que apenas o Sumo Sacerdote poderia pronunciar no dia do Yom Kippur - ele o dissera: diante de 
todos ele o dissera, arrastado por uma força incontrolável, movido pela mesma força que o levaria, pouco depois, a se revelar: era ele o Messias, o escolhido por Deus para destronar os governantes das nações e restaurar o reino de Israel - ele, Sabatai Zvi: em seus ombros, o peso do mundo; ao seu redor, uns poucos discípulos.

Cegos, no entanto, são os homens para os intentos divinos. Primeiro, a expulsão de Esmirna: depois de meses da errância causada pelos filhos israelitas de Amalek - judeus incapazes de conhecer a face de seu próprio Messias, não tardarão a pagar por seu erro -, finalmente lhe veio um consolo. Estava em Constantinopla quando Abraham ha-Yakini, o bondoso e velho sábio, trouxe o raro manuscrito com palavras tão claras e precisas: "no ano de 5386, nascerá Mordecai Zvi, aquele que será chamado Sabatai: aquele que derrotará o grande dragão, aquele que ocupará o Trono da Glória" - quantas vezes não repetiu em seu silêncio essas palavras: mais fortes se tornavam as forças que o buscavam como um sopro divino; e assim soube, em seu espírito, os novos passos de sua jornada.

Salônica o reconheceu: novos discípulos o procuravam, tão ansiosos por provar suas palavras quanto aqueles que, no deserto, ansiavam pelo gosto do maná. Lá Sabatai se revelou, perante a multidão, como o Ein-Sof - seu rosto, a única face de Deus; lá se casou com a Torá, saudado por um povo em delírio. Quando outra vez foi expulso, não fraquejou: acatou com imenso júbilo a punição - agora conhecia o seu caminho: se cegos são os homens, tudo enxergam os olhos de Deus. Com gosto se lançou (outra vez) à errância: passou por Atenas e Alexandria, voltou a Esmirna, chegou a Constantinopla - e, conquanto as sombras lutassem para retornar ao seu espírito, suas vitórias pareciam cada vez mais frágeis e efêmeras. No Cairo lhe deram a riqueza - mas de que serve o ouro para o Messias? Por isso a entregou aos seus discípulos: aos talmudistas e cabalistas cedeu cada inútil moeda: seu tesouro, afinal, era outro: que banquete seria capaz de lhe saciar a excelsa alma - que conforto poderia lhe dar paz igual à que alcançava flagelando seu próprio corpo, vendo as gotas de sangue a respingar pelas paredes, sentindo a queimar por dentro o estômago vazio?

Não poderia, contudo, permanecer ali; se aproximava o ano de 1666: nos números, o augúrio do apocalipse. Urgia partir para Jerusalém - com a certeza de que lá, na Cidade Santa, também reconheceriam seu esperado Messias. Deus enchera sua voz com força e encanto; Deus lhe dera a arma com a qual venceria a desconfiança dos infiéis. Gostava de entoar os salmos; contudo, sua abençoada voz era capaz de desvelar o sentido sagrado mesmo nas canções mais vulgares e não tardou a reunir novas multidões, espíritos cuja sede apenas ele poderia saciar; eles então o seguiam, tantos fervorosos fiéis, e se pudessem beberiam as lágrimas que derramava, em copioso pranto, sobre os túmulos dos homens pios. Depois, quando vieram até ele pedir dinheiro para que a cidade pudesse se proteger dos turcos, sabia a quem recorrer: outra vez partiu a caminho do Cairo: lá onde Halabi, seu rico discípulo, o aguardava, sempre disposto a servir à causa messiânica - a causa de que dependia todo o povo israelita, todo o povo que lhe pertencia: a ele, Sabatai Zvi, por tanto tempo esperado, a quem mais pertenceria o Trono da Glória?

\section{2/Ruach}

O pai o censurava: imaginava coisas demais; embora fosse um estudante aplicado, era dado a fabulações, a idéias sem pé nem cabeça - a tal ponto que ele, o pai, pensara várias vezes em suspender as aulas de Talmude e Cabala que o filho vinha tendo com Jacob Hagis. Não que houvesse qualquer problema com o professor, sem dúvida um dos mais importantes cabalistas de Jerusalém, mas não estaria tudo aquilo fazendo mal para a cabeça do jovem? Muita especulação pode causar danos irreparáveis à mente fértil em fantasias, e o jovem Natã sempre fora dado a esse tipo de coisas. E agora todos aqueles nomes e números, tanta matéria para 
maiores fabulações era sem dúvida preocupante - para o pai, mas não para Hagis, que enxergava, para o jovem, um futuro promissor: tinha talento, era esforçado; disciplina é algo que com o tempo se conquista, e as próprias dificuldades impostas pelo estudo certamente acabariam por refrear a prolífica imaginação de Natã, conforme se fosse afastando a juventude. Mas há cabeças que parecem nunca entrar nos trilhos; aliás, é decerto desse tipo a cabeça daquele homem que há não muito tempo chegou a esta cidade e se hospedou perigosamente próximo à casa do jovem Natã; um homem estranho, é o que todos comentam, dado a excentricidades e a drásticas variações de humor; anda cercado por um bando de seguidores, pessoas ainda mais estranhas do que ele, que nele ousam ver indícios de santidade.

O pai o censurava; contudo, nenhuma censura seria capaz de refrear o vigor com que este jovem se lança aos estudos, o rigor com que observa cada mitzvá - ele, que em grande pureza se dedicou a estudar a Torá até os vinte anos, que depois pôs em prática o tikun à maneira de Luria a fim de livrar sua alma de todas as faltas - não alguma que ele cometera, ele que era puro até as pontas de cada um dos fios de seu cabelo, mas porque o atemorizavam os pecados que sua alma pudesse haver cometido em algum estágio anterior da transmigração. Depois, quando aos vinte anos começou a estudar o grande livro chamado Zohar, começou a entrever ao seu redor os anjos enviados por Deus, claro sinal de que sua alma finalmente fora purificada; estava, afinal, preparado para a revelação, a mais importante de toda a sua vida.

Há uma semana houve a festa de Purim: desde aquele dia, nenhum alimento tocou a boca de Natã. Neste momento ele está trancado num quarto, sozinho; o dia amanhece - um dia quente, que exala um calor abafado: há uma nuvem de vapor por todos os lugares. O suor cola as roupas ao seu corpo esguio: gotas descem por sua testa, escorrem entre os pêlos do seu bigode e da sua curta barba - as gotas de suor que se mesclam às lágrimas que lhe brotam dos olhos. Seu corpo fraco e magro começa subitamente a tremer; suas pernas fraquejam, seus joelhos se dobram - e ele finalmente tomba de joelhos: surdo o som que preenche o quarto. Seus olhos, arregalados, contemplam o inefável: é estranha esta ascensão que mais se assemelha, na verdade, a uma descida: quando ele percorre as câmaras e os palácios, lutando contra os anjos que se atiram violentamente contra o seu corpo para fazê-lo recuar, quando sente nascer uma imensa chama dentro de seu próprio espírito - consegue, apesar de tudo, resistir; e enfim penetra aquela esfera onde soa um altíssimo hino, que ressoa em cada parte de sua alma - eis, Natã, o Trono da Glória ante os teus olhos, e agora o que será de ti?

Permanece no chão, caído, durante um dia e uma noite: seus olhos não piscam, seu corpo não pára de tremer; seus dedos estão rígidos, sua boca aberta está cheia de uma estranha espuma; não sente dor, nada sente: apenas um êxtase que o arrebata, que domina por inteiro seu espírito, que não permite que deixe aquele sagrado lugar - é Deus quem se mostra ante seus olhos, cada uma das dez faces do Ein-Sof; e surge então a voz, uma voz que nasce e ressoa dentro de sua alma, fazendo vibrar todo o seu corpo e ecoando em seu coração - "no ano de 5386, nascerá Mordecai Zvi, aquele que será chamado Sabatai: aquele que derrotará o grande dragão, aquele que ocupará o Trono da Glória". Havia se preparado: enfim lhe veio a revelação.

Então ele corre de encontro àquele homem, pois sabe que é dele que tratam essas palavras; aquele homem que, surpreso com suas palavras, revela que, na verdade, veio até aqui à procura dele - à procura de Natã: ouviu falar sobre sua sabedoria, talvez ele possa aplacar os males que lhe afligem a alma - as mudanças de humor, as excentricidades cujo sentido nem ele mesmo conhece, motivadas por irresistíveis forças que, sem qualquer motivo, lhe tomam a alma e o corpo; e Natã, este roto Natã, ainda sentindo em seu corpo as reverberações do êxtase, se lança aos seus pés e diz, com uma voz que, embora rouca, soa surpreendentemente alta: "Tu, tu és o Messias, a ti está destinado o Trono da Glória!" 
Desde então o acompanha: é seu companheiro, seu braço direito; é quem dá sentido aos seus atos. Quando retorna para Jerusalém levando o dinheiro que protegerá os judeus dos turcos, Sabatai tem diante de si o seu profeta: ele, Natã, que anuncia a alta voz o advento da esperada era - pois aí está o Messias, como não o reconhecem, ele que irá levar de volta as Dez Tribos à Terra Sagrada, o que cavalgará um imenso leão que derrotará, com suas garras, um colossal dragão de sete cabeças; ninguém entende o que ele está falando, mas todos parecem muito impressionados com as palavras ditas aos gritos, já podem quase ver o leão e o dragão a lutar diante dos seus olhos. E quando são expulsos pelos rabinos, não oferecem resistência: não é este o seu lugar, afirma o austero Natã, nem é mais esta a Cidade Santa, seria perda de tempo ficar mais tempo aqui.

Já ninguém os pode manter fora dos muros de Esmirna: há ali uma multidão que o saúda Longa vida ao nosso Rei, nosso Messias!, gritam em uníssono enquanto invadem a sinagoga. É sua, inteira, a cidade: implacável, depõe os opositores, nomeia seus aliados - eles, os justos, os sábios, os verdadeiros judeus. Se espalha a notícia que logo vence as fronteiras: dos estrangeiros aos cristãos, todos já sabem que o Messias enfim veio o mundo; se agitam as comunidades que habitam em terras longínquas: é preciso partir para a nova Israel. Contudo, quando lá chegarem, já não encontrarão quem procuram.

Natã sabe: como agir sem conhecer a vontade divina? Diz o profeta ao seu Messias: devem seguir para Constantinopla; é chegado o esperado ano: quando atravessarem os muros da cidade, Deus fará o milagre: a coroa será arrancada da cabeça do sultão e pousará, sem luta ou sangue, sobre a cabeça de Sabatai Zvi - a ele o trono, a ele a glória. Assim entram, jubilosos: há cânticos, há festa, há lágrimas; mas quando atravessam os portões da cidade, outros se aproximam: eles os cercam, suas mãos ímpias tocam o Messias; de nada adiantam os protestos, os gritos, as ameaças dos discípulos. Eis a vontade de Deus, diz um sereno Natã, aplacando os seguidores; Sabatai apenas ouve, parece assustado. Seguem os três, em silêncio.

Ficam por dois meses presos em Constantinopla; depois, são levados para a prisão de Migdal'Oz, a fortaleza. Chegam na véspera de Pessach: Natã consegue que tragam para a cela um cordeiro; Sabatai o sacrifica, comem a carne, a gordura - onde há erro? Louvado seja Deus que restaurou tudo o que era proibido, diz o Messias, a língua a deslizar pelos largos lábios. Embora em plena prisão, vive como um rei ao lado de sua altiva rainha: é preciso aguardar o milagre - o milagre que todos esperam. Por todo o mundo, os judeus acompanham a sina de seu Messias: nas sinagogas esplendem as iniciais - S. Z.; as efígies do Rei Sabatai e do Rei David brilham, lado a lado; Louvado seja nosso Rei e Senhor, dizem as preces, Louvado seja Sabatai Zvi, o Messias do Deus de Jacó. Por toda a parte, os judeus seguem as reformas por ele promulgadas: do jejum se faz a festa, o Yom Kippur será abolido - eis a idade messiânica: regozijai-vos, judeus!

Até o dia em que Sabatai é levado para ver o sultão: à direita seu profeta, à esquerda sua rainha - que venha o divino milagre. Os três se entreolham; sobre eles, os olhos hostis - do silêncio recende o medo. O físico do sultão se aproxima. Pára diante deles; severo os fita, e pousa as mãos em seus ombros; sussurra algo em seus ouvidos - o brilho nos olhos de Sabatai, que fita Natã; com um gesto, consente. Sem hesitação, arranca e lança ao chão as vestes judaicas, com força e fúria: é Natã quem coloca sobre sua cabeça o turbante turco - é essa, afinal, a coroa do Messias? O sultão o acolhe entre os seus; o leva até a varanda - ele e os seus companheiros. Quando o vêem sair, os discípulos murmuram entre si, trocando gestos aturdidos; ele se aproxima e os saúda com um gesto. Deus fez de mim um ismaelita, diz em plácida e bovina voz, Ele ordenou, assim foi feito. O silêncio parece abraçar o mundo: judeus, onde a sua vergonha? 


\section{3/Neshamah}

Ela, sua rainha: seu nome é Sara. Tem longos cabelos castanhos que descem pelas costas em belas ondas avermelhadas; tem olhos grandes, escuros como abismos, que parecem atrair para ti tudo que os cerca; tem um rosto perfeitamente arredondado, lábios carnudos e um queixo delicado e suave; quando caminha, arrasta consigo todos os olhares, principalmente os masculinos: embora não seja tão alta, tem um porte gracioso e levemente arrogante que causa uma forte impressão; tem seios não muito grandes, mas rijos e bem esculpidos: usa vestidos com grandes frestas que deixam à mostra as precisas curvas; tem pernas grossas e ancas largas que gosta de oscilar enquanto caminha: suave, um andar de felina.

Qualquer um que a veja percebe que domina os segredos da sedução; teve tempo suficiente para aprendê-los, desde o longo tempo em que, ainda tão jovem, trabalhou como prostituta em Amsterdã; não o fez por escolha: era ainda uma criança quando os conflitos em Chmielnicki a condenaram à orfandade - quando seu nome era ainda Sarai. Foi encontrada sozinha, esquálida e faminta, por cristãos que devotamente a trancaram naquele convento onde passou os dez piores anos de sua vida; por sorte - ou terá sido um milagre? - conseguiu fugir: nos braços de um amante - o primeiro de tantos -, viajou para Amsterdã, onde enfim encontrou sua independência: não com ele, mas nas ruas.

Os bons atraem a inveja alheia - sempre foi assim; por isso, teve que aprender a se virar sozinha. Era invejada pelas outras prostitutas: por que era tão cobiçada, logo ela que era mais jovem, que era mais inexperiente? Porque ela, ao contrário de tantas outras, gostava do que fazia - ou ao menos passava essa impressão para os homens com quem se deitava: selvagem e insaciável, bela Sarai, templo venal - bem sei que és mulher formosa à vista; desfilava vestida com luxo: tantos presentes ganhava de tantos fiéis servidores seus - tinha Yesod entre as pernas, diria um de seus clientes, eminente cabalista, e na carne todo o esplendor. O que as outras não percebiam é que, de fato, amava seu ofício; o que as outras não entendiam é que ali, nos braços de estranhos, encontrava enfim o afeto que na infância lhe fora negado. Fonte de todo o amor: ela, a bela Sarai, a terna amante e a eterna irmã.

Mais difícil era, entretanto, conseguir se habituar à efemeridade das coisas: ninguém ousaria desposá-la - demorou a perceber; não: já o havia percebido, mas o espírito não se aquietava; como aceitar que eles viessem e partissem assim, sem qualquer aviso, abandonando-a de uma hora para a outra? Prometiam voltar, prometiam ficar com ela: Sarai, és muito formosa: serás minha esposa; depois partiam, desapareciam: com ela ficavam os nomes - na memória o rosto, no corpo os presentes, mas tudo era pouco; nada calava, sobretudo, a ausência que latejava dentro do jovem peito; por isso, talvez sem querer, começou a empunhar a afiada espada do sarcasmo: quando juravam fidelidade, quando confessavam seu amor, quando diziam que deixariam suas esposas para se casarem com ela, apenas ria; indignados, protestavam: por que não confiava neles? Por que ria, Sarai cruel? Ela negava; Não digas isso, porque te riste, diziam magoados. E partiam; e não voltavam.

Quando ouviu falar sobre o Messias, sua imaginação se excitou: seu peito foi povoado por uma mescla de sentimentos: o restaurador de Israel, o descendente de Davi: precisava vê-lo, precisava se aproximar dele - desejo que se foi aumentando conforme ouvia os relatos sobre seus feitos: havia em torno dele uma aura de pureza que atraía multidões - pessoas de todos os povos, até mesmo não-judeus; em seus olhos habitava a paz, seu toque curava doenças - alguns diziam que era capaz de ressuscitar os mortos; o que a princípio era curiosidade foi se tornando, aos poucos, uma obsessão: não apenas sentia que precisava vê-lo - mais do que isso: precisava tocá-lo, precisava senti-lo, porque ele - apenas ele - seria, de fato, capaz de ouvi-la, de entendêla, de... Por isso também ela partiu. 
Não era uma multidão, como ela esperava: era apenas um bando de pessoas - judeus, cristãos, pessoas de todos os tipos; no centro do grupo, havia um homem surpreendentemente comum baixo, com um rosto gordo e olhos sonolentos; ao seu lado, um homem mais jovem, esguio e de feroz semblante, falava aos gritos numa língua que ela não entendia; Sarai observou a reação dos que os cercavam: alguns os fitavam com assombro, outros observavam com indiferença; uns poucos murmuravam e riam. De repente, o homem feroz se calou e olhou com austeridade ao seu redor; então cedeu lugar ao homem baixo, que deu alguns passos à frente, se aproximando da heterogênea platéia; seus olhos eram grandes, redondos, bondosos; de repente, começou a cantar, um voz fina e melodiosa, Dize la nuestra novia, ¿Cómo se yama el cabeyo?, palavras que ela então não entendia, mas que agora já conhece bem, No se yama cabeyo sino seda de labrar - depois ele falou que a música tratava da relação dos homens com Deus, ela bem se lembra: a novia e seu amado, uma longa explicação, tão bela quanto inspiradora - enquanto falava, sua voz hesitava: tinha lágrimas nos olhos, muitos ao seu redor também pareciam comovidos; e também ela - que, não mais podendo se conter, correu em sua direção: quiseram segurá-la, mas ele a tomou em seus braços - e ali ficaram, os dois abraçados, chorando em meio à multidão.

Soube que aquele era o Messias; por ordem dele, ela os acompanhou e dormiu na mesma casa onde se haviam hospedado. Na manhã seguinte, o homem esguio - agora já sabia que seu nome era Natã - lhe falou sobre a sua sina: ela, Sarai, estava destinada a ser a esposa do Messias; no dia seguinte se casaram perante a multidão - agora, de fato uma multidão se reunira para assistir ao casamento entre o Messias e a Grande Prostituta, como Natã anunciara por toda a Jerusalém. Durante a cerimônia, enquanto ela chorava, seu corpo trêmulo de júbilo, o profeta anunciava para o povo o plano messiânico; falava aos gritos, e por vezes se voltava, olhava dentro de seus olhos e dizia, aos gritos, coisas cujo sentido ela não compreendia - Te prostituíste com os filhos do Egito, e também te prostituíste com os filhos da Assíria, porque eras insaciável, mas nem ainda assim ficaste farta; depois multiplicaste as tuas prostituições na terra de Canaã até Caldéia, e nem ainda assim tu te fartaste; a tua perversidade e as tuas abominações, tudo isso tu levarás - ela apenas ouvia, o corpo trêmulo de júbilo. A Sarai, tua mulher, não chamarás mais por esse nome, Sarai: Sara será o seu nome.

Desde então, jamais o deixou: este homem que nunca tocou o seu corpo, embora freqüentemente se entregasse os atos mais devassos - jamais com mulheres - quando o perseguiam os filhos de Naamá: assim dizia Natã, que sempre tinha uma explicação para as excentricidades de Sabatai; mesmo seus atos mais disparatados, suas mais graves violações ganhavam um sentido elevado no discurso do profeta: quando, em meios aos banquetes em que se empanturrava de sangue e chelev, pronunciava em êxtase o nome divino; ou quando, aos berros, se punha a testar o poder divino, ordenando a Deus que o afastasse dos klipot, começando em seguinda a blasfemar, aos prantos - para tudo isso Natã tinha uma explicação: tudo eram ma'asim zarim, dizia o profeta que o contemplava com enlevo e espanto; com a chegada do Messias, o processo do tikun é completado: para um novo mundo, uma nova Torá: as novas leis de Sabatai.

Contudo, os judeus fraquejaram. Como não compreenderam que o Messias precisava descer, ele mesmo, até a fortaleza da escuridão para completar sua tarefa - o Messias entre as serpentes -, e que fora esse o sentido de sua conversão? Como não enxergaram que seu intento era resgatar os ismaelitas, fazer de todos eles judeus - não seguidores de um velho judaísmo, mas da nova fé de Sabatai? A verdade é apenas essa: fraquejaram - fracassaram: abandonaram seu próprio Messias, condenado ao esquecimento. 
Primeiro os judeus; depois, também os turcos - ao fim, todos os deixaram, exceto aquele bando de fanáticos que ainda agora o rodeia. Sara sabe que são loucos: fazem seus próprios máasim zarim, como se tivessem eles esse poder; seus atos, contudo, são desprovidos de qualquer sentido - não superam as mais torpes blasfêmias. Natã, também ele definitivamente enlouquecido, está com eles, vagando por aí; mas não Sabatai - Sara o mantém a salvo: ela, de fato, é quem o mantém vivo. Ele é capaz de descer das alturas aos abismos de uma hora para a outra; não raro se vê cercado por demônios - como ontem, quando, em pânico, por pouco não se lançou através janela. Está agora amarrado à cama, no miserável quarto em que vivem - o único lugar que Sara é capaz de pagar: já está velha, não consegue mais tanto dinheiro - apesar de sua beleza; apesar de conhecer tão bem os segredos da sedução.

Um homem se aproxima: velho, magro, tem poucos dentes e um nariz adunco. Trocam umas poucas palavras. Sobem juntos a estreita escada, logo, chegam ao quarto parcamente iluminado. Sara se despe; Sara o despe, depois se deita com ele - o magro corpo entre as suas grossas pernas. Apenas uma fina cortina divide em duas partes o pequeno aposento: de um lado, o leito em que Sara atende o seu cliente; de outro lado, o leito em que jaz Sabatai, amarrado, fitando o teto com olhos túmidos e arregalados. Sara não o abandonará; pouco importa que acreditem ou não no que ele diz; ele, o único que jamais tocou o seu corpo, é o único a quem ela de fato se entrega: ela, Sara, sua rainha - talvez só ela o tenha entendido.

* Henrique Marques-Samyn é tradutor, poeta e escritor. Mestre em Psicologia Social pela Universidade do Estado do Rio de Janeiro, Brasil. 